\title{
DETERMINATION OF SUNSCREEN COMPOUNDS IN WATER SAMPLES BY SILICONE ROD EXTRACTION
}

\author{
A.GIORDANO ${ }^{1, *}$, P. RICHTER ${ }^{2}$, K. LEIVA' ${ }^{2}$ L. ASCAR ${ }^{2}$ \\ ${ }^{1}$ Departamento de Química Inorgánica, Facultad de Química, Pontificia Universidad Católica de Chile Av. Vicuña Mackenna 4860, \\ Casilla 306, Correo 22, Macul, Santiago, Chile \\ ${ }_{2}^{2}$ Departamento de Química Inorgánica y Analitica, Facultad de Ciencias Químicas y Farmacéuticas, Universidad de Chile, \\ Casilla 233, Santiago, Chile. \\ (Received: October 29, 2012 - Accepted: January 14, 2013)
}

\begin{abstract}
Silicone rod extraction (SR) is a siloxane-based methodology for the extraction of organic pollutants from aqueous samples with similar principle extraction as the stir bar sorptive extraction (SBSE). In this study the SR was coupled with HPLC-DAD and employed for the extraction and quantification of selected UV filters in water and seawater samples. Chromatographic parameters were optimized as well as the main sorption/desorption conditions for 4-methylbenzylidene camphor (4MBC) and octyl-methoxy cinnamate (OMC) from both river water and seawater samples. After optimization of the proposed method the following variables were selected: $25,0 \mathrm{~mL}$ of sample volume, 3 hour extraction, $1250 \mathrm{rpm}$ as stirring velocity and $2 \mathrm{~mL}$ methanol as desorption solvent. The recoveries from seawater samples were $76.6 \%$ for $4 \mathrm{MBC}$ and $85.9 \%$ OMC. In river water samples recoveries of $69.8 \%$ and $82.4 \%$ for $4 \mathrm{MBC}$ and OMC, respectively, were observed when salt was added to the sample. Linear calibration curves were obtained in the corresponding matrix and quantification limits below $1.86 \mu \mathrm{g} \mathrm{L}^{-1}$ were obtained. A comparison between the proposed method and the SBSE alternative revealed that SR can be use as a reliably and cheap methodology for the determination of sunscreens.
\end{abstract}

Keywords: 4-methylbenzylidene camphor, octyl-methoxy cinnamate, silicone rod extraction, water samples

\section{INTRODUCTION}

Sunscreen compounds are common additives in cosmetic formulations, which are capable of filtering or blocking UV radiation. Several types of compounds are used for this purpose, including titanium oxide which reflects the radiation, and other organic compounds which absorb UV radiation. ${ }^{1}$ The main types of compounds used for this purpose, approved by the Public Health Institute (Instituto de Salud Publica, ISP) in Chile ${ }^{2}$, are p-aminobenzoic acid (PABA) and its derivatives, benzophenones (BP), methylbenzylidene-camphor derivatives (MZC), and methoxycinnamate derivatives.

Recent studies have shown that many of these compounds have estrogenic and anti-androgenic activity when entering through the skin $^{3}$. Studies have been published showing that derivatives of methoxycinnamate and methylbenzylidene-camphor displace estradiol and estrogen receptors ${ }^{4}$.

These compounds have different ways to reach the environment. The main source is the industrial wastewater and domestic wastewater discharge, reaching the water treatment plants, where they can enter directly to natural waters or to the soil by biosolids application. A second direct source is recreational activities such as swimming and other water sports, allowing the entry of these compounds into surface waters ${ }^{3}$.

The determination of compounds used as sunscreen is performed by using gas chromatography (GC) for more volatile compounds or by high performance liquid chromatography (HPLC) for non volatile compounds, being the main problem the low concentration found in environmental matrices, requiring necessarily a previous extraction/preconcentration step. Determination in sewage and seawater using solid phase microextraction (SPME) ${ }^{5}$ or from water samples by solid phase extraction (SPE) have been reported ${ }^{6}$, along with single drop microextraction (SDME) ${ }^{7}$ and micelle liquid extraction ${ }^{8}$. Stir bar sorptive extraction (SBSE) coupled with thermal desorption have been used for the determination of sunscreen in river water, with higher sensitivity ${ }^{9}$. The same methodology was also applied to sewage water ${ }^{1}$.

Other methodologies with similar characteristics to SBSE extraction as rotating disk sorptive extraction (RDSE) $)^{10}$ and silicone rod extraction (SR) ${ }^{11}$ have being developed in the last years. Those have the advantages to be flexible, robust and less expensive. The SR also presented the advance that the rods commercially available are made with polydimethylsiloxane and other additives, such as vinyl methyl phenyl polysiloxane or silicic acid esters, while the SBSE or RDSE present just PDMS, targeting extraction only to apolar compounds.

Extraction with SR has been applied to the extraction of organic pollutants from water samples. Recoveries of up to $97 \%$ of polycyclic aromatic hydrocarbons were obtained using the SR extraction with solvent desorption ${ }^{12}$, recoveries up to $89 \%$ for the determination of polychlorinated biphenyls (PCBs) ${ }^{11}$, and of $69-93 \%$ for polybrominated diphenyl esthers extracted from water samples ${ }^{13}$.

In the present work, the sunscreen extraction/preconcentration from river water and seawater using silicone rod was assessed for 4-methylbenzylidenecamphor and octyl-methoxycinnamate, due to their high $\log \mathrm{K}_{\text {ow }}$ value. The extraction method was optimized and applied in real samples.

\section{EXPERIMENTAL}

\subsection{Materials}

4-methylbenzylidene-camphor (4MBC) and octyl-methoxycinnamate (OMC) were purchased from Merck (Darmstadt, Germany). Stock solutions were prepared weekly in methanol and stored in dark bottles a $-4^{\circ} \mathrm{C}$. All solvents were HPLC grade from Merck. Sodium chloride, magnesium sulphate and other salts were obtained either from Merck or Sigma-Aldrich (Milwaukee, WI, USA).

The water used was obtained from a Direct-Q3 Nano-pure water system from Millipore (Schwalbach, Germany). Nitrogen 5.0 was purchased from AGA (Santiago, Chile) and used for final extract evaporation.

Phenyl-vinyl-methyl polysiloxane from a $2 \mathrm{~mm}$ diameter flexible rod by Goodfellow (Bad Nauheim, Germany) was used as phase extraction.

\subsection{Chromatographic determination}

Instrumentation employed for HPLC-DAD determination was a WATERS 1525 binary pump coupled to a WATERS 299 photodiode detector with a 20 $\mu \mathrm{L}$ sample loop injector. A Symmetry C18 column $(5 \mu \mathrm{m} \times 4.6 \times 25 \mathrm{~mm})$ with a guard column of the same material $(8 \mathrm{~mm} \times 3 \mathrm{~mm})$. Acetonitrile:water $(80: 20)$ at $1 \mathrm{~mL} \mathrm{~min}-1$ flow was used for the isocratic elution of the analytes at room temperature. Spectrum identification of each UV filter was performed and wavelength of $300 \mathrm{~nm}$ was used to quantification.

\subsection{Seawater preparation}

Artificial seawater was prepared daily according to the ASTM International standard practice for the preparation of substitute ocean water ${ }^{14}$.

\subsection{Silicone rod extraction}

Prior to use, the SR were washed with methanol and dried at $120^{\circ} \mathrm{C}$. Water sample consisting in a variable volume of nano-pure water or artificial seawater was spiked with UV filters stock solution at $20 \mu \mathrm{g} \mathrm{L}^{-1}$ concentration was placed in an amber vial with a magnetic stirred. A $2 \mathrm{~cm}$ long silicone rod, previously washed with methanol, was placed in the vial and the sample was stirred at $1250 \mathrm{rpm}$ a room temperature. To desorption of the analytes the SR was dried with clean soft tissue and placed in ambar vial with $2 \mathrm{~mL}$ methanol and stirred a $1250 \mathrm{rpm}$ for 30 minutes. The extract obtained was evaporated to $0.5 \mathrm{~mL}$ under a gentle stream of nitrogen. All steps were conducted without exposure of the sample to artificial and/or sunlight. 


\subsection{SBSE extraction}

Stir bars (SBSE) coated with PDMS $(0.5 \mathrm{~mm}$ film thickness, $10 \mathrm{~mm}$ length) were obtained from Gerstel (Mülheim and der Ruhr, Germany) and were used to compare extraction efficiency. Prior to use, the stir bars were conditioned into a vial containing $10 \mathrm{~mL}$ of methanol. To perform the extraction, the bar was placed into an amber vial containing $25.0 \mathrm{~mL}$ of spiked water sample at $20 \mu \mathrm{g} \mathrm{L}^{-1}$ concentration. After the extraction the bar was dried with free lint tissue and placed in a vial with $2.0 \mathrm{~mL}$ of methanol for $30 \mathrm{~min}$ for desorption. The extracted water was then evaporated to $0.5 \mathrm{~mL}$ under a gentle stream of nitrogen. All steps were conducted without exposure of the sample to artificial and/or sunlight. After every extraction the bar was cleaned with additional $20.0 \mathrm{~mL}$ of methanol for 30 minutes.

\subsection{Determination of $4 \mathrm{MBC}$ and $\mathrm{OMC}$ in water samples}

Water and seawater samples from Algarrobo, IV Region, Chile were used to apply the proposed methodology. Such samples were subject to the extraction/desorptive procedure in optimum conditions. After that, these samples were enriched with the analytes at $20 \mu \mathrm{g} \mathrm{L}^{-1}$ concentration and extracted again to determine recoveries.

\section{RESULTS AND DISCUSSION}

\subsection{Optimization of the silicone rod extraction}

Variables involved in the extraction were optimized in order to increase the analytes recoveries and preconcentration factor with minimum solvent.

Figure 1 shows the studies conducted in spiked water to optimize the stirring speed. An increase in the speed increases the chromatographic response, as usual in this type of extraction, such as SPME and SBSE ${ }^{1,9}$. However since the SR is not damaged during the process, the maximum speed was selected, considering these an advantage over the SBSE extraction, where the PDMS coating is damage by the constant friction between the stir bar and the glass surface ${ }^{15}$.

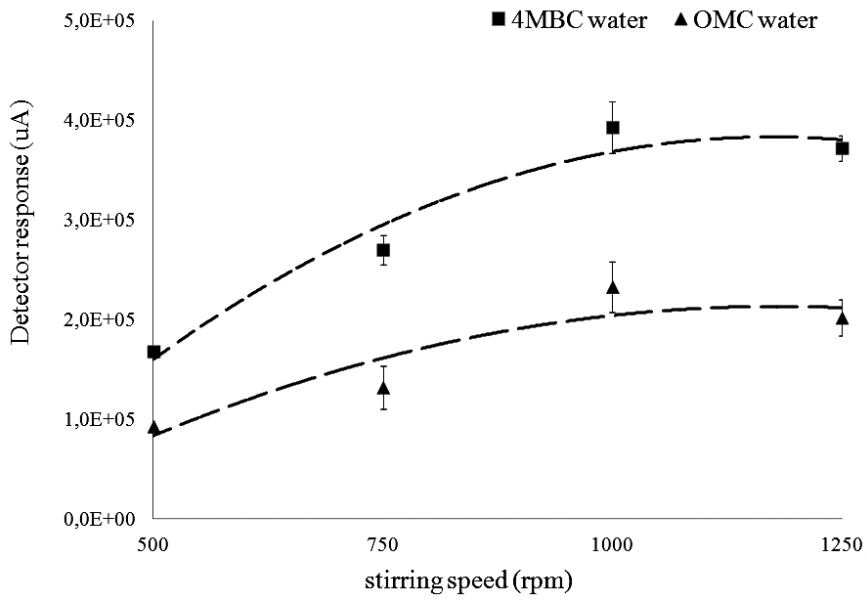

Figure 1. Effect of the stirring speed on the extraction performance.

The extraction time was also optimized considering a $25.0 \mathrm{~mL}$ of either water or seawater sample. As shown in Figure 2, extraction equilibrium is achieved after 3 hours. Similar extraction times are reported by other authors ${ }^{16}$, and are consequent with the kinetic theory of this type of extraction ${ }^{17}$. Figure 2 also shows a difference between the extraction efficiency from water and seawater, which can be explained by a natural salting out effect in the seawater sample, which is proven to enhance the analytes sorption ${ }^{6}$. In the case of water sample, sodium chloride was added to a concentration of $3 \%(\mathrm{w} / \mathrm{w})$ to increase the ionic force and improve the analyte recoveries.

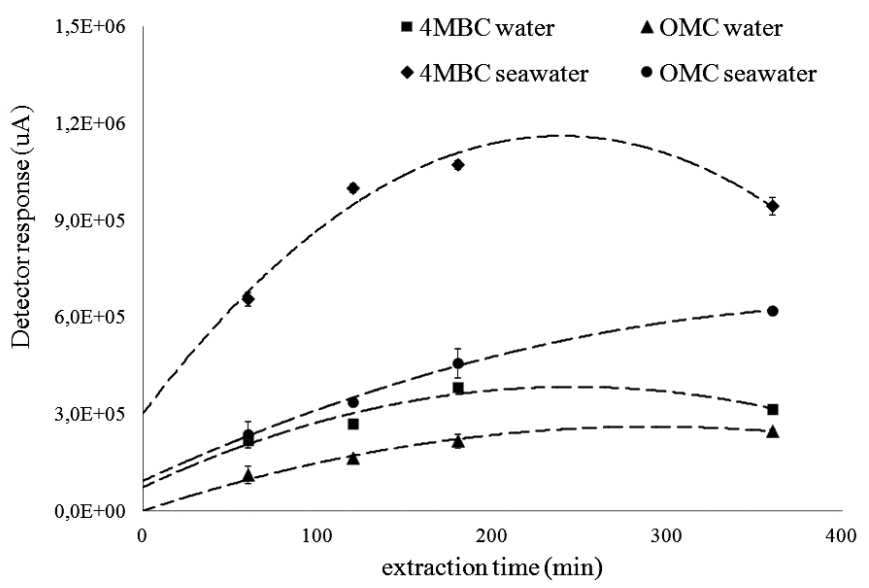

Figure 2. Extraction time profiles for the analytes in water and seawater samples.

A study of the influence of the sample volume in the extraction was performed at a 3 hours extraction by spiking the same amount of UV filters in different volumes of aqueous sample. The results show an increment in the response when the sample volume decreased. It is known that analyte mass transport is more efficient when the aqueous volume to polymeric phase volume ratio is lower. These are later defined as the phase ratio has a direct influence in the extraction efficiency since the siloxane-based extractions recovery is described by equation 1 :

$$
\text { Recovery } \left.=\frac{\left(\mathrm{K}_{\mathrm{ow}} / \mathrm{b}\right)}{1+\left(\mathrm{K}_{\mathrm{ow}} / \mathrm{b}\right)} \quad \text { (equation } 1\right)
$$

where $\mathrm{K}$ is the analyte distribution coefficient and $\mathrm{b}$ is the phase ratio ${ }^{17}$. Since the polymeric volume is approximately $75 \mu \mathrm{L}$, a quantitave recovery is expected when the sample volume is between $5 \mathrm{~mL}$ and $25 \mathrm{~mL}$, however in order to increase the preconcentration factor $25.0 \mathrm{~mL}$ was chosen.

Desorptive conditions of solvent, solvent volume and time of desorption were determined. Only HPLC compatible solvents were tested considering that no swelling or dissolving of the SR phase were observed. Methanol was selected and used in a volume of $2 \mathrm{~mL}$ to cover completely the SR during the desorption step. No further studies were conducted to optimized the solvent volume, considering that to improved the preconcentration factor of the method it was necessary to reduce the final volume to $0.5 \mathrm{~mL}$ A total time of $30 \mathrm{~min}$ were selected for the back extraction of analytes, even when there was no significantly difference between 20 and 30 minutes when comparing the response. There was no carry over effect in a second desorption, but considering the low cost of the polymeric phase, it was not reusable.

\subsection{Analytical features}

The recovery of the analytes at optimum experimental conditions is shown in Table 1. Recoveries up to $86 \%$ were obtained from the seawater samples, considering the salting out effect; while in water samples similar values were obtained when adding sodium chloride. When no salt was added the recovery in water samples was below $34 \%$. Considering a reported $\log \mathrm{K}_{\mathrm{ow}}$ of 5.14 for $4 \mathrm{MBC}$ and 5.8 for $\mathrm{OMC}^{8}$, a complete recovery of the analytes may not be reached since the extraction performance decreases when lowering the partition constant, similar to others siloxane based extraction ${ }^{16}$ as shown in equation 2. However for quantitative analysis, it is not necessary for the analytes to be completely extracted as long as the extraction is carefully timed and experimental conditions remain constant $t^{5}$.

Table 1. Recovery obtained at selected conditions.

\begin{tabular}{|c|c|c|c|c|}
\hline \multirow{2}{*}{} & \multicolumn{2}{|c|}{ SR } & \multicolumn{2}{c|}{ SBSE } \\
\cline { 2 - 5 } & water $^{*}$ & seawater & water* & seawater \\
\hline 4MBC & 69.8 & 76.6 & 68.1 & 77.5 \\
\hline OMC & 82.4 & 85.9 & 77.9 & 72.4 \\
\hline
\end{tabular}

*water samples with added salt 
Figures of merit of the method can be observed in Table 2. The reproducibility study of the extraction for the UV filter under the same conditions, reflect values between 10 to $20 \%$ for the same day and a similar value when comparing between days. The high values can be explained since a total equilibrium is not reach, and to the possible compound loss by absorption in vial or by photodegradation. However, these values are comparable to those reported by other authors when using solvent desorption ${ }^{18}$.

Calibration curves in a concentration between $10 \mu \mathrm{g} \mathrm{L}^{-1}$ and $100 \mu \mathrm{g} \mathrm{L}^{-1}$ were built for each UV filter in order to establishing the detection limit and the quantification limit of the method ${ }^{19}$. Table 2 summarizes the results obtained for the calculation of LOQ and LOD. It is expected that lower detection limits would be obtained when using thermal desorption as reported by other authors $^{1}$. Correlation coefficients were between 0.95 and 0.99 . Low values can be attributed to the reproducibility.

Table 2. Analytical parameter for the analytes in water samples.

\begin{tabular}{cccccc}
\hline Water & Calibration curve & $\begin{array}{c}\text { Correlation } \\
\text { coefficient }\end{array}$ & $\begin{array}{c}\mathrm{LOD} \\
\left.(\mu \mathrm{g} \mathrm{L})^{-1}\right)\end{array}$ & $\begin{array}{c}\mathrm{LOQ} \\
(\mu \mathrm{g} \mathrm{L})^{-1}\end{array}$ & $\begin{array}{c}\% \mathrm{RSD} \\
(\mathrm{n}=6)\end{array}$ \\
4MBC & $\mathrm{y}=4.63 \mathrm{E} 3 \mathrm{x}+1.21 \mathrm{E} 3$ & 0.9752 & 0.39 & 1.30 & 17.8 \\
OMC & $\mathrm{y}=3.81 \mathrm{E} 3 \mathrm{x}+1.13 \mathrm{E} 3$ & 0.9509 & 0.56 & 1.86 & 16.1 \\
Seawater & & & & & \\
4MBC & $\mathrm{y}=2.09 \mathrm{E} 3 \mathrm{x}+7.32 \mathrm{E} 3$ & 0.9814 & 0.27 & 1.41 & 16.8 \\
OMC & $\mathrm{y}=3.29 \mathrm{E} 3 \mathrm{x}+5.06 \mathrm{E} 2$ & 0.9904 & 0.24 & 0.80 & 13.8 \\
\hline
\end{tabular}

\subsection{SBSE extraction}

A study that compares the extraction efficiency between SR and SBSE was carried out at the optimum conditions obtained for the SR extraction, the result can be observed in Table 1. In addition to the recuperation values, similar reproducibility values were observed. A slightly difference between both methods can be explained by variation in the extraction phase polarity: SBSE has a PDMS polymeric phase less polar that the PVMPS phase present in the SR.

The SBSE extraction show the advantage of having the magnetic stirrer as part of the stir bar, which made the manipulation of the phase easier than the SR since an external magnetic stirred is place during the extraction and the back extraction steps. However with the SR extraction similar extraction efficiency can be reached with a cheaper extraction phase and a faster methodology because no cleaning between extractions is needed and simultaneous extractions can be performed since the SR is not reusable.

\subsection{Determination of $4 \mathrm{MBC}$ and $\mathrm{OMC}$ in water samples}

The extraction method was applied to samples of water that came from Algarrobo, Chile and the results can be observed in Table 3. Concentrations between those observed by the method weren't detected in the real samples, since the sample points were taken in a less populated areas and the concentration of these analytes can decrease by sun degradation. However, when enriched the sample with sunscreens to a concentration of $20 \mu \mathrm{g} \mathrm{L}^{-1}$ and extracted using the same conditions, the recovery of the analytes is in accordance with the ones obtained during the extraction optimization.

Table 3. Concentration and recovery of $4 \mathrm{MBC}$ and $\mathrm{OMC}$ in real samples.

\begin{tabular}{|c|c|c|c|}
\hline & \multirow{2}{*}{$\begin{array}{l}\text { without spiking } \\
\text { concentration } \\
\left(\mu \mathrm{g} \mathrm{L}^{-1} \pm \mathrm{SD}\right)\end{array}$} & \multicolumn{2}{|c|}{ with spiking } \\
\hline & & $\begin{array}{l}\text { concentration } \\
\left(\mu \mathrm{g} \mathrm{L}^{-1} \pm \mathrm{SD}\right)\end{array}$ & $\begin{array}{c}\text { recovery } \\
(\%)\end{array}$ \\
\hline \multicolumn{4}{|l|}{ River water } \\
\hline $4 \mathrm{MBC}$ & n.d. & $13 \pm 3$ & 67 \\
\hline $\mathrm{OMC}$ & n.d. & $16 \pm 3$ & 80 \\
\hline \multicolumn{4}{|l|}{ Seawater } \\
\hline $4 \mathrm{MBC}$ & n.d. & $15 \pm 2$ & 76 \\
\hline $\mathrm{OMC}$ & n.d. & $18 \pm 4$ & 89 \\
\hline
\end{tabular}

n.d.: not detected

\section{CONCLUSIONS}

The application of the SR extraction with HPLC-DAD for the determination sunscreens in water and seawater samples was established. The optimum conditions allow the recovery of $4 \mathrm{MBC}$ and $\mathrm{OMC}$ between 68 and $86 \%$ depending on the sample, with reproducibility lower than $20 \%$. As comparison, the SBSE technique was implemented, showing similar results in recovery and reproducibility when using the same extraction parameters. However the SR extraction presents advantages over the SBSE extraction, since it's cheaper and less time consuming.

\section{ACKNOWLEDGEMENTS}

The authors thank Proyecto FONDECYT 3110110 for financial support.

\section{REFERENCES}

1. R. Rodil, M. Moeder, J. Chromatogr. A, 1179, 81 (2008).

2. https://www.ispch.cl/RegistrosISP/fimenu.asp

3. D. Giokas, A. Salvador, A. Chisvert, Trends Ana. Chem., 26, 360 (2007).

4. M. Schlumpf, P. Schmid, S. Durrer, M. Conscience, K. Maerkel, M. Henseler, M. Gruetter, I. Herzog, S. Reolon, R. Ceccatelli, O. Faass, E. Stutz, H. Jarry, W. Wuttke, W. Lichtensteiger, Toxicology, 205, 113 (2004).

5. D.A. Lambropoulou, D.L. Giokas, V.A. Sakkas, T.A. Albanis, M.I. Karayannis, J. Chromatogr. A, 967, 243 (2002).

6. D.L. Giokas, V.A. Sakkas, T.A. Albanis, J. Chromatogr. A, 1026,289 (2004).

7. N.E. Mazonakis, P.H. Karathanassi, D.P. Panagiotopoulos, P.G. Hamosfakidi, D.A. Melissos, Anal. Chim. Acta, 467, 261 (2002).

8. D.L. Giokas, V.A. Sakkas, T.A. Albanis, D.A. Lambropoulou, J. Chromatogr. A, 1077, 19 (2005).

9. M. Kawaguchi, R. Ito, N. Endo, N. Sakui, N. Okanouchi, K. Saito, N. Sato, T. Shiozaki, H. Nakazawa, Anal. Chim. Acta, 557, 272 (2006).

10. P. Richter, C. Leiva, C. Choque, A. Giordano, B. Sepúlveda, J. Chromatogr. A. 1216, 8598 (2009).

11. L. Montero, P. Popp, A. Paschke, J. Pawliszyn, J. Chromatogr. A, 1025, 17 (2004).

12. P. Popp, C. Bauer, A. Paschke, L. Montero, Anal. Chim. Acta, 504, 307 (2004).

13. R. Montes, I. Rodríguez, E. Rubí, R. Cela, J. Chromatogr. A, 1143, 41 (2007).

14. ASTM International, Section eleven, Annual Book of ASTM Standards, Wiley-Vch, USA, 2010.

15. W. Liu, Y. Hu, J. Zhao, Y. Xu, Y. Guan, J. Chromatogr. A. 1095, 1 (2005).

16. M. Van Pinxteren, A. Paschke, P. Popp, J. Chromatogr. A, 1217, 2589 (2010).

17. I. Bruheim, X. Liu, J. Pawliszyn, Anal. Chem. 75, 1002 (2003).

18. Z. Qin, L. Bragg, G. Ouyang, J. Pawliszyn, J. Chromatogr. A, 1196, 89 (2008).

19. Y.Vasquez-Martínez, R. Villegas, A. Villa, G. Massiff. J. Chil. Chem. Soc., 48, 554 (2011) 